\title{
La lectura en Huesca en el siglo XVI
}

\author{
Laura FONTOVA SANCHO \\ (Archivos Municipales de Somontano de Barbastro)
}

\section{Resumen}

Este artículo se basa en un estudio más amplio sobre bibliotecas privadas localizadas en documentación notarial del siglo XVI en la ciudad de Huesca. A partir de los inventarios de las bibliotecas se analizan las lecturas citadas en relación con los propietarios de estas colecciones. Este tipo de estudios permite contextualizar los índices de lectura en el marco de situaciones sociodemográficas similares, en una época primigenia de aparición y consolidación de la imprenta en España.

Palabras clave: Lectura; Lectores; Huesca; Siglo XVI; Protocolos notariales.

\section{Reading in Huesca in the sixteenth century}

\section{Abstract}

This article is based on a wider study of private libraries recorded in $16^{\text {th }}$ century notarial documents from Huesca. The inventories of these collections are analyzed in relation to their owners. This kind of study contextualizes measures of reading among similar social and demographic groups at the time of the appearance and consolidation of printing in Spain.

Keywords: Reading; Readers; Huesca; Sixteenth Century; Notarial documents. 


\section{Panorámica de la ciudad de Huesca en el siglo XVI}

Huesca, ciudad de poco más de mil casas, de las más antiguas deste reyno y la mas principal despues de Zaragoza en Cortes y otros ajuntamientos. Esta hedificada no muy lejos de los Montes Pirineos...

No es rico ni pobre el comun della... Tiene de termino por todas partes poco mas de media legua salvo hazia Zaragoza que tendra dos.

Ay poco trato en ella y menos pasto: pero grande justicia...

La gente es noble y principal porque ay muchos ydalgos señores de los mas de los lugares que estan en torno, pero no son muy ricos...

La Universidad de Huesca es la mas antigua de España; leese en Plinio serlo ya en tiempo de Quinto Sertorio... Sus rentas ascienden a 1356 escudos.

(Un informe del siglo XVI sobre el Obispado de Huesca) ${ }^{1}$

Esta es la visión que ofrecía un comisionado de Roma, Juan Pérez de Artieda, canónigo de la Catedral de Zaragoza, cuando se le envío en 1565 a realizar un informe sobre las ciudades y territorios que formaban la Diócesis de Huesca, esto es: Huesca, Barbastro y Jaca. Hay que situar la emisión de este informe en el proceso de desmembración de la diócesis de Huesca que finaliza en 1571 de la mano del Obispo del Frago en el que Barbastro forma un obispado independiente del de Huesca y Jaca que continúan permaneciendo juntos.

Como se lee en esta descripción de Huesca, se presenta una ciudad de unos 4.500 habitantes. $^{2}$

\footnotetext{
1 Antonio Durán Gudiol, «Un informe del siglo XVI sobre el Obispado de Huesca», en Argensola, 32 (1957), pp. 273-297.

2 Asimilando el término casas al de fuego, que era como se contabilizaba a los núcleos familiares en los que había un cabeza de familia responsable del sustento de sus miembros y era sujeto pasivo del pago de los tributos. Diversos estudios cifran el equivalente de fuego entre 4,5-6 habitantes. V. Francisco Javier DOMENECH VILLAGRASA, «Los recuentos y censos de población: ¿cómo abordar su estudio?» en Metodología de la investigación científica sobre fuentes aragonesas. Jornadas (6 ${ }^{a}$. 1990. Graus), Zaragoza, Universidad de Zaragoza, Instituto de Ciencias de la Educación, 1991, pp. 420-465; José Antonio SALAS AusENS,
} 
El informe habla de una ciudad con baja nobleza, con un comercio que empieza a florecer y con una base económica principalmente agrícola. Una ciudad que abre las puertas al estado moderno, ayudada de una posición estratégica por su posición privilegiada en las rutas comerciales de la época (situada en el Camino Real de Zaragoza, en la ruta que une Aragón con Francia a través de Ayerbe, Jaca y Canfranc) entre otros.

Alude además el informe a la condición universitaria de Huesca, que dice poseer la más antigua Universidad de España. La universidad de Huesca se fundó en 1354 por Pedro IV a la que le otorgó ser la de mayor importancia en España después de Lérida y le concedió el privilegio de ser la primera del reino de Aragón. Las disputas que mantuvo con Zaragoza, que pretendió tener también una Universidad, finalizaron cuando Carlos V, sin llegar a concederle la razón a Zaragoza, terminó autorizando el funcionamiento de las dos universidades. La oscense, aunque con el tiempo fue perdiendo fuerza, durante sus años de esplendor fue foco de interés de numerosas órdenes religiosas que se instalaron en la ciudad atraídas por los estudios que ofrecía: Facultades mayores de Teología, de Cánones, de Leyes y de Medicina, la Facultad menor de Artes, y como estudios previos a todas estas facultades se hallaba la Escuela de Gramática donde se enseñaba latín, oratoria y retórica. Todo esto, unido al hecho de que el primer impresor de Huesca, Juan Pérez de Valdivielso, se instalase en 1575 contratado por la Universidad, nos sitúa ante una ciudad donde confluyen diversos factores de interés para realizar un estudio sobre los índices de lectura en el primer siglo de la imprenta.

\section{Metodología de trabajo e indicadores de lectura}

El presente artículo presenta sucintamente los resultados obtenidos a partir de la investigación de las bibliotecas privadas registradas en los inventarios postmortem localizados en 1.025 protocolos notariales. De este conjunto documental producido por los notarios que ejercieron su oficio en Huesca capital desde 1501 hasta 1600, se obtuvo una muestra de 720 inventarios. De los cuales, 279 fueron pertinentes para la investigación pues eran los que poseían libros o material de escritura o de archivo (libros, escrituras, mobiliario como estanterías, atriles o facistoles, resmas de papel, plumas, tinteros...), esto es, todo aquel objeto material que delatase la pertenencia a un individuo con habilidades de lectoescritura. 170 de esos 279 inventarios mencionaban libros. Cierto es que el hecho de que se poseyesen libros no significa que su propietario los hubiera leído todos, quizás la mayor parte de volúmenes solo los acumulara, pero sí implica que él o alguien de su entorno tenía interés por ello. Con seguridad varios de estos libros habrían sido objeto de préstamo pues este fue un modo habitual en la época de

«Demografía aragonesa en la Edad Moderna», en Jornadas sobre el estado actual de los estudios sobre Aragón (2 ${ }^{a}$. 1979. Huesca), Zaragoza, Universidad de Zaragoza, Instituto de Ciencias de la Educación, 1980, pp. 535-543.

Titivillus, ISSN 2387-0915, ISSN-e 2603-9966, 3 (2017), pp. 67-90 
circulación de los libros y difusión de su lectura. Un claro ejemplo se aprecia en la cita «y mas dizen tiene mossen Anton Castillo, una Suma de Ostiense y mas [sobrepuesto: en poder de] Lorenço Costa tiene emprestado a Decio, super decretales». ${ }^{3}$

Amplia es la literatura que estudia las ventajas e inconvenientes del manejo de los protocolos notariales como fuente principal de una investigación. ${ }^{4}$ El protocolo notarial, como se ha demostrado en muchas ocasiones, es una valiosísima fuente de información para el conocimiento real de una sociedad, pues en ellos el notario recoge todos los actos jurídicos realizados ante su presencia como fedatario público. En concreto, el inventario postmortem es el acto por el cual el notario levantaba acta de todos los bienes muebles que había en el interior de la casa o casas de un difunto (incluidos animales y cantidad de grano almacenado si procedía). Todo ello recorriendo cada una de las habitaciones y anotando lo que veía en ellas. Aunque muchas son las ventajas para su utilización, los estudios también muestran reservas al respecto, pues el inventario postmortem no era un requisito legal de obligado cumplimiento. Solo se levantaba inventario cuando el difunto había dejado deudas que saldar, o cuando había hijos menores de 25 años de edad que debían heredar, o cuando había una requisición legal por la que se había apresado o embargado al propietario (en este caso no sería posmortem), o cuando había fallecido sin testar. Es decir, el inventario postmortem no lo realizaba toda la población. Además, el inventario muestra una fotografía de los bienes que hay en una casa que, ciñéndonos al mundo del libro, podría ofrecer otra composición de estas bibliotecas en otros momentos de la vida de esos lectores ya difuntos. En los resultados de mi investigación ${ }^{5}$ se ha podido comprobar esta falta de obligatoriedad legal en la realización de inventarios, ya que al comparar el número total de inventarios hallados en los protocolos con el número de defunciones inscritas en los registros parroquiales conservados se constató que los 279 inventarios localizados representan solamente el $5 ’ 16 \%$ de la población, en consecuencia los 170 inventarios que tienen libros solo atañen al 3,14\% de la misma. No obstante, este porcentaje no invalida el uso de esta fuente pues, como se verá a continuación, los resultados ofrecen

3 Archivo Histórico Provincial de Huesca (AHPH). Protocolo de Andrés de Castro, 1063, ff. 582-590. Inventario postmortem de micer Francisco Domínguez. (1590, diciembre, 20).

${ }^{4}$ Sobre la utilidad de esta fuente aplicada a la investigación sobre el libro véanse los estudios sobre esta fuente realizados por Bartolomé BENNASSAR, «Los inventarios postmortem y la historia de las mentalidades», en La documentación notarial y la historia: actas del II Coloquio de metodología histórica aplicada, Santiago de Compostela, Junta de Decanos de los Colegios notariales de España, Universidad de Santiago, 1984, pp. 139-146; Hortensio SOBRADO CORREA, «Los inventarios post-mortem como fuente privilegiada para el estudio de la historia de la cultura material en la Edad Moderna», en Hispania, LXIII/3, 215 (2003), pp. 825-862.

${ }^{5} \mathrm{El}$ presente artículo procede de la información obtenida durante el desarrollo de mi tesis doctoral cuya edición está en fase de preparación.

Titivillus, ISSN 2387-0915, ISSN-e 2603-9966, 3 (2017), pp. 67-90 
ya una cifra estimada de 2.500 títulos de libros en manos de un pequeño porcentaje de población del que se conoce el inventario de su biblioteca al dar fe de ella el notario en un documento público.

No obstante, el análisis de las lecturas, en lo que respecta a Huesca, arrojó índices de lectura cuyas cifras son similares a las del resto de estudios comparativos que había en otras zonas geográficas. Si se tiene en cuenta que estas ratios se obtienen de la relación existente entre los inventarios totales y los pertinentes, se obtendría un índice de lectura durante el siglo XVI en Huesca del 23,61\%. En el cuadro realizado por Bernabé Prieto, completado con los resultados de algunos estudios posteriores, se aprecia que el porcentaje de índices lectores en las ciudades españolas y algunas europeas se situaba entre el 20 y el $30 \%$.

\begin{tabular}{|c|c|c|c|}
\hline \multicolumn{4}{|c|}{$\begin{array}{l}\text { PORCENTAJES DE POSEEDORES DE LIBROS (SIGLOS XV-XVII) } \\
\text { (ANÁLISIS COMPARATIVO DE AL GUNAS CIUDADES }\end{array}$} \\
\hline CIUDAD & AUTOR & PERÍODO & $\%$ \\
\hline AMIENS & Labarre & $1503-1576$ & 19,9 \\
\hline BARCELONA & Peña Díaz & $1473-1600$ & 26,7 \\
\hline BESANÇON & Grinevald & $1680-1790$ & 20,7 \\
\hline CASTELLÓN & Gil y Salavert & $1527-1698$ & 13 \\
\hline HUESCA & Fontova & $1501-1600$ & 23,6 \\
\hline FLORENCLA & $\mathrm{Bec}$ & $1413-1453$ & 3 \\
\hline FLORENCLA & $\mathrm{Bec}$ & $1570-1608$ & 5 \\
\hline LORCA & Cerdá Díaz & $1670-1700$ & 56,7 \\
\hline MADRID & Prieto Bernabé & $1550-1650$ & 31,7 \\
\hline MÁLAGA & Vincent & Finales s. XVI & 26,6 \\
\hline OESTE FRANCÉS & Quéniart & $1697-1790$ & 34 \\
\hline OVIEDO & Barreiro & s. XVII & 20,6 \\
\hline SALAMANCA & Weruaga Prieto & $1650-1725$ & 23 \\
\hline SEVILLA & Maillard & $1550-1600$ & 25 \\
\hline VALENCLA & Berger & $1475-1550$ & 24,8 \\
\hline VALLADOLID & Bennassar & s. XVI & 12 \\
\hline ZARAGOZA & Pedraza Gracia & $1501-1521$ & 22 \\
\hline
\end{tabular}

Tabla 1: Índices de lectura. Fuente: Elaboración propia a partir del cuadro elaborado por Prieto Bernabé. ${ }^{6}$

${ }^{6}$ José Manuel PrIETO BeRnABÉ, Lectura y lectores: la cultura del impreso en el Madrid del Siglo de Oro (1550-1650), Mérida, Junta de Extremadura, 2004. 


\section{Prácticas de lectura}

Pero más allá del fenómeno estadístico, siguiendo las bases asentadas en 1993 por Chevalier de lo que se denominarían «prácticas de lectura», ${ }^{7}$ surgen obras que permiten atisbar aspectos como los modos de leer y quién leía. ${ }^{8}$

Conforme avanza el siglo XVI la estructura social es más compleja y la gente acude cada vez más al notario, que al final de los documentos, junto al nombre de los testigos, consigna con frecuencia la frase «por no saber leer ni escribir». En una sociedad con un elevado índice de analfabetismo, como lo es la del quinientos, había tres formas de transmisión del mensaje: la icónica, icónica-verbal y la escrita. La escrita reservada a una minoría letrada (no una élite sociocultural, puesto que había muchos nobles que no sabían escribir, ya que se consideraba un oficio manual y por tanto servil. Los mensajes procedían de las clases dominantes: el clero por medio de los sermones y, la realeza y la nobleza mediante las hazañas de antepasados, lo que servía para perpetuar su situación de privilegio. En alusión al modo de transmisión del mensaje, Bouza acuña el término «disglosia cultural» que define como el uso voluntario y discriminado del lenguaje por parte de esa minoría letrada que

\footnotetext{
7 Maxime CheVAlIER, Lectura y lectores en la España del siglo XVI y XVII, Madrid, Ediciones Turner, 1976, a partir del análisis de lecturas como El Lazarillo, La Celestina, El Quijote o la Épica culta, planteaba tres hipótesis que proporcionan un giro a las cuestiones que hasta entonces se hacían los investigadores:¿Quién sabe leer?, ¿Quién tiene posibilidades de leer libros? y ¿Quién llega a adquirir la práctica del libro?. Sus conclusiones fueron: la existencia de un elevado índice de analfabetismo entre la población, el elevado precio de los libros, y la falta de interés por la lectura de entretenimiento, que es la que él analiza.
}

${ }^{8}$ Destacan las aportaciones de Alberto MANGuel, Una bistoria de la lectura, Madrid, Alianza, Fundación Germán Sánchez Ruipérez, 1998; de Guglielmo Cavallo, Roger CHARTIER (dirs.), Historia de la lectura en el mundo occidental, Madrid, Taurus, 2011 (Pensamiento). En la península son significativas y marcan un nuevo rumbo las obras de Fernando J. BouZA Álvarez, Del escribano a la biblioteca: la civilización escrita europea en la Alta Edad Moderna (siglos XV-XVIII), Madrid, Síntesis, 2010 (Historia Universal Moderna; 5); de Antonio CASTILLO GÓMEZ, Entre la pluma y la pared: una bistoria social de la escritura en los siglos de oro, Madrid, Akal, 2006. Ambas centradas en la indivisibilidad del uso social de la escritura y la adquisición y consolidación de la lectura. Durante todo este tiempo y alternando estos tipos de investigación surgen bastantes obras que combinan ambos métodos: conocimiento de la producción impresa y de la actividad impresora de un determinado territorio; conocimiento del libro y sus componentes; análisis y conocimiento de los lectores como modo de acercamiento a las prácticas de lectura, todos ellos, partiendo, en su mayoría, de fuentes primarias. Vid. Manuel José PeDRAZA Gracia, Lectura y lectores en Zaragoza: 1501-1521, Zaragoza, Prensas Universitarias de Zaragoza, 1998 (Humanidades; 31); Prieto Bernabé, Lectura y lectores...; Manuel Peña Díaz, El laberinto de los libros: historia cultural de la Barcelona del Quinientos, Madrid, Fundación Germán Sánchez Ruipérez, 1997; Anastasio Rojo VegA, Ciencia y cultura en Valladolid: estudio de las bibliotecas privadas de Los siglos XVI y XVII, Valladolid, Universidad de Valladolid, 1985; Philippe BERGER, Libro y lectura en la Valencia del Renacimiento, Valencia, Edicions Alfons el Magnánim, 1987; Natalia MAILLARD Álvarez, Lectores y libros en la ciudad de Sevilla (1550-1600), Barcelona, Ediciones Rubeo, 2011 (Memoria del tiempo). 
elegiría la transmisión y comprensión del mensaje en función de las circunstancias que le rodean. ${ }^{9}$

Heredera de la lectura en voz alta practicada en la Edad Media, aunque también había, en mucha menor medida, lectura silenciosa, se tiende en la Edad Moderna a la práctica de la lectura silenciosa. Así, se encuentran tres tipos de lectura: colectiva, en círculo reducido, y en silencio.

Paralela a la evolución de la sociedad, y a la adaptación y cambios morfológicos en el libro (formato, ampliación de márgenes para anotaciones, introducción de capítulos...), surgen tres tipos de libros que Pedraza concreta en: libros de leer, de rezar y libros herramienta. ${ }^{10}$ Lo habitual es que libros de rezar y herramienta se leyeran en silencio, mientras que los libros de leer lo fueran en voz alta. Aunque todos pueden ser leídos en voz alta y en silencio: un breviario se leería en silencio. Si bien podía recitarse la «Vida del Gran Capitán» en voz alta, ante un público embelesado, o una de las vidas de mártires de la leyenda áurea o del flos sanctorum recitarse desde un púlpito; o por el contrario, leerse en silencio en el rincón más apartado de la casa, pues la lectura en silencio llama a la meditación y a la reflexión favoreciendo la capacidad crítica del lector.

Probablemente, la Silva de varia lección de Pedro Mejía no la leería de igual manera el zapatero oscense Martín Marañón menor, ${ }^{11}$ que el notario de Huesca Miguel Ordoñez alias Palencia, ${ }^{12}$ pues ambos lectores atraídos por la sencillez del lenguaje del libro y la variedad de temas que ofrece Mejía en su obra, se acercarían a sus enseñanzas por placer y curiosidad, o acaso alguno de ellos lo haría con una mayor inquietud intelectual. ${ }^{13}$

\section{Lectores y bibliotecas}

Teniendo en cuenta lo expresado con anterioridad sobre la representatividad de la fuente elegida a la hora de extraer conclusiones que generalicen las prácticas de lectura de toda la población, indicar que se localizaron en bibliotecas privadas 2.500 títulos de obras citadas — no

\footnotetext{
${ }^{9}$ Fernando BouZa Alvárez, Del escribano a la biblioteca: la civilización escrita europea en la Alta Edad Moderna (siglos XV-XVI), Madrid, Síntesis, 2010 (Historia universal moderna; 5), p. 28.

10 Manuel José PedraZa Gracia, «El análisis de los inventarios para el estudio del lector y de la lectura: bibliotecas privadas y lecturas en tiempos de Carlos I», en José María Díez Borque (dir.), Bibliotecas y librerías en la España de Carlos V, Barcelona, Calambur, 2015, pp. 11-32.

11 AHPH. Protocolo de Martín Lizana y Rosillo, 921, ff. 100-103 (1579, mayo, 14).

12 AHPH. Protocolo de Sebastián de Canales, mayor, 685, ff. 840 v - 851 (1557, noviembre, 26).

13 AHPH. Protocolo de Martín Lizana y Rosillo, 921, ff. 100-103 (1579, mayo, 14); AHPH, Protocolo de Sebastián de Canales, mayor, 685, ff. 840 v-851 (1557, noviembre, 26) respectivamente.
} 
volúmenes-. ${ }^{14}$ Entre los 279 inventarios con los que se ha trabajado solamente en 176 se consignaba el oficio del difunto, en 86 no se indicaba ni se podía deducir la pertenencia del finado a un grupo social específico y 17 inventarios pertenecían a instituciones.

La adscripción a un estrato social ofrece los siguientes resultados: nobleza (9 inventarios), clero (71), mercaderes (12), profesiones liberales (43) -médicos, juristas, cirujanos_- y el resto a la base de la población urbana (41) - -artesanos, sastres, zapateros, carpinteros, plateros, libreros, apotecarios y agricultores-. ${ }^{15}$

\footnotetext{
${ }^{14}$ De estas obras, 2.136 se localizaron en los inventarios notariales y 734 pertenecieron a la biblioteca del Obispo del Frago, biblioteca descrita en el interior de un proceso eclesiástico que ha sido estudiada por Manuel José PEDrazA Gracia, El conocimiento organizado de un hombre de Trento: la biblioteca de Pedro del Frago, Obispo de Huesca en 1584, Zaragoza, Prensas Universitarias, 2011 (Humanidades; 90).

15 Cada investigador, como es natural, se apropia de distintas clasificaciones de grupos sociales para la época estudiada, pudiendo verse algunas diferencias en las agrupaciones realizadas. El establecimiento de la clasificación de estos estratos sociales para el siglo estudiado ha venido influenciada principalmente por dos premisas: primera, por el diferenciador contenido de la colección del difunto; segunda, por una simplificación de realidades sociales difíciles de solventar con los escasos datos que sobre el difunto se consignan en el inventario y que hacen, en ocasiones, complejo adscribirlo a un grupo social o a otro. La categorización de un grupo indepediente de mercaderes obedecería a la primera premisa; mientras que a la segunda, respondería la denominación de base de la población urbana. Vid. José María DíEz Borque (dir), Isabel Díez MÉNGuez (ed.), Bibliotecas y clase social en la España de Carlos V (1516-1556), Barcelona, Calambur, 2015, pp. 11-32, donde se ofrece el estudio de las bibliotecas en base a bibliotecas pertenecientes a la nobleza, profesionales liberales e intelectuales, clero, trabajadores, oficios del libro, cargos públicos. Los mercaderes se consideran dentro de las bibliotecas de trabajadores (mercaderes, oficiales mecánicos, campesinos y ganaderos).
} 


\begin{tabular}{|c|c|c|}
\hline OCUPACION & No INVENTARIOS & $\%$ NO INVENTARIOS \\
\hline NOBLEZA & 9 & 3.23 \\
\hline CLERO & 71 & 2545 \\
\hline MERCADERES & 12 & 4,30 \\
\hline PROFESIONES LIBERALES ${ }^{107}$ & 43 & 1541 \\
\hline $\begin{array}{l}\text { BASE DE LA POBLACIÓN } \\
\text { URBANA }\end{array}$ & 41 & 14.70 \\
\hline TOTAL OACIO & 76 & 63.09 \\
\hline OCUPACION & No INENTARIOS & $\%$ No INVENTARIOS \\
\hline CON OFICIO & 76 & 63,09 \\
\hline SIN OFICIO & 86 & 30,82 \\
\hline INSTITUCIONES & 17 & 6,09 \\
\hline TOTAL IMVENTARIOS & 279 & 100 \\
\hline
\end{tabular}

Tabla 2: Distribución de inventarios por estrato social. Fuente: Elaboración propia.

La mayor parte de las bibliotecas se encuentran principalmente en manos de miembros del clero y de profesionales liberales - especialmente médicos y juristas-. En disonancia de lo que apuntan otros investigadores, que señalan a la nobleza como uno de los grupos con mayores bibliotecas, en el caso de Huesca solo se han hallado 9 inventarios con libros o con material de escritura. De los 9 inventarios solo 5 poseen libros. El mayor corresponde a Gracia de Mur, ${ }^{16}$ viuda del ciudadano Martín de Lierta, aunque por el tipo de libros que cita "20 libros de escritura» probablemente se trate de libros de cuentas. No ocurre lo mismo con el inventario de Tomasa de Suelves en el que, aunque solo se mencionan 8 librillos, especifica que estaban escritos en latín. ${ }^{17} \mathrm{Si}$ se recuerda el contexto de la ciudad citado al principio del artículo, se alude a una nobleza rural «ydalgos señores de los mas de los lugares que están en torno, pero no son muy ricos...». Posiblemente, esa pertenencia a la baja nobleza distinga la escasa presencia de libros en sus bibliotecas, frente a otras bibliotecas nobiliarias estudiadas por otros investigadores en otras regiones que sí refieren numerosas colecciones que contienen hasta 100

16 AHPH. Protocolo de Luis Navarro, 962, ff. 164-167 (1580, junio, 16).

17 AHPH. Protocolo de Sebastián de Canales, mayor, 1104, ff. 200 (1579, abril, 4). 
libros. ${ }^{18}$ Señalar que uno de los inventarios localizados solo relaciona los libros que el difunto infanzón Alonso Cortés tenía en una capilla fundada por él, ${ }^{19}$ por lo que es probable que en su casa hubiera más libros.

En especial, el alto clero es el que tiene las más ricas colecciones. La biblioteca del obispo Diego de Arnedo de la que solo conocemos el número de libros, 540. Las bibliotecas de varios monjes del Monasterio de Montearagón, como el prior del claustro Domingo de Ciria con 97 libros; la del Abad de Montearagón Alonso de Aragón con 50 libros; o la del canónigo Eliseo Adrián con 147 libros.

Entre los profesionales liberales, en ocasiones es difícil discernir, a partir de los datos que ofrece el inventario, y en especial en el caso de los juristas, si pertenecen además al clero. A veces, se indica la condición in utroque o doctor en ambos derechos; otras se dice que es «maestro» $\mathrm{y}$, solo el resto de bienes inventariados o la localización de la vivienda o habitación confirma la pertenencia a una orden religiosa. En cualquier caso, la existencia en Huesca de la Universidad ofrece la posibilidad de encontrar bibliotecas bien nutridas como la del jurista Jaime Morcat ${ }^{20}$ con 164 libros, o la del también jurista Francisco Domínguez ${ }^{21}$ con 115 libros. O las del doctor en derecho Juan Serra y el doctor en medicina Miguel Ram que tenían 132 y 180 libros, respectivamente. Igualmente, la colección de 106 libros de Juan Torregrosa, doctor en teología y maestro mayor del Estudio de Huesca de la que ya se ha hablado, estaría entre estas bibliotecas.

18 DíEz BorQue, «Las bibliotecas de la nobleza», pp. 75-90, al tratar las bibliotecas de la nobleza da un porcentaje de 37,03\% de colecciones de libros que contiene de 1 a 50 ejemplares, y del $51,84 \%$ las que contienen de 51 a 100 ejemplares. El resto se sitúa por encima. Sin duda, son unas bien nutridas bibliotecas las que configuran el resultado obtenido del estudio de 29 inventarios de nobles realizados en unas tempranas fechas, entre 1516 y 1556 . Vid. nota 14.

19 AHPH, Protocolo de Martin Gistau, 864, ff. 74 v - 82 v. (1575, septiembre, 10)

${ }^{20}$ La biblioteca de Jaime Morcat tiene 3 inventarios en el intervalo de 2 años y medio. Vid. AHPH. Protocolo de Guillermo Costa, 5967, ff. 248-257 (1555, septiembre, 7); AHPH. Protocolo de Jerónimo Climente, 1072, ff. 81 - 87 v (1558, febrero, 24); y AHPH. Protocolo de Sebastián de Canales, mayor, 1490, ff. 38 v - 41 v (1558, enero, 8) donde solo dice tener «un arca ferrada llena de scripturas viejas...ciento y sesenta y un libros entre grandes y pequenyos de derecho canonyco y civil con los fueros y reportorio...». Como los otros dos inventarios dan una cifra de 163 y 164 títulos identificados, se mantiene la composición en 164 libros. Por supuesto, esta biblioteca solo se contabiliza una vez.

${ }^{21}$ La biblioteca del jurista Francisco Domínguez tiene dos inventarios: uno el que se hace a su muerte, y otro en la capitulación matrimonial que hace su viuda, Catalina Adrián, al casarse en segundas nupcias, un año más tarde, con el también jurista Juan Miguel de Olzina, también profesor de la Universidad. En el primero se relacionan 115 títulos, mientras que en el segundo son 123. Se toma como referencia de conjunto los 115 libros que son los que tenía el jurista cuando murió. Los inventarios pueden verse en AHPH. Protocolo de Andrés de Castro, 1063, ff. 582-590 (1590, diciembre, 20); y AHPH. Protocolo de Andrés de Castro, 1063, ff. 355-375 v (1591, agosto, 30). Al igual que la de Morcat, ambos inventarios se han considerado como una sola colección. 
Otras bibliotecas de profesionales, menores en cuanto a número de libros, serían las de notarios formadas, claramente por libros herramienta, cuyas colecciones oscilaban entre los 16 y 22 libros, tales como las de Jaime de La Raga y Martín de Lizana, ambos notarios públicos.

Entre los mercaderes, se citan naipes y un pequeño número de libros sin identificar como los que tiene el mercader Juan Pastor: «quatro dozenas y media de naypes..., seys libros entre malos y buenos». Lo habitual es que en estos inventarios no se detallen los libros de lectura y solo se identifique acaso algún breviario. El notario suele indicar con más cuidado los libros de cuentas y escrituras del negocio, y cuando anota los libros que probablemente eran para leer se refiere a ellos «entre malos y buenos» o como «dos o tres libros viejos». Estos últimos en poder del mercader Jaime de Fanos.

Las bibliotecas de artesanos y campesinos suelen tener pocos libros, algunos para leer y otros para aprender. Como entretenimiento leería «dos romances de coplas» el calderero Juan del Fierro. ${ }^{22}$ Colección que aumentaría en la partición que su viuda Ana del Compás, hace dos meses después, anotando: «el libro de las fabulas de Ysopo, unos libricos, el uno de refranes y avisos, y la otra parte de la coronica del inclito Infante don Hernando, dos romances de coplas». Esta búsqueda de la lectura por placer se observa, igualmente, en el único «libro de romance de caballerias» que había en la casa del labrador Pedro del Val. Sí, resulta curioso, que en estas bibliotecas, donde la mayoría de los libros son de cuentas, es donde también se pueden ver citados mayor cantidad de efímeros como estampas y naipes. Algunos sirvieron a Juan de la Rúmbide como «paperes de muestras de officio de fustero». Otros, como las «7 docenas de naipes finos a 20 sueldos la docena ( 7 libras) y las 12 docenas de naipes de Tolosa y maestros con algunos jugados a 10 sueldos docena (6 libras)», se encuentran entre la mercancía que vende el droguero Juan de la Fuente.

Destaca la biblioteca del mazonero, Gil de Brabán, compuesta en 1547 por 32 libros que según como se citan «Item trenta y dos pieças de libros entre grandes y pequenyos de letra de emprenta y uno blanquo...» eran todos de leer menos uno que debía ser para llevar las cuentas, o quizás un libro que se destinara «para escribir memorias». Este escultor, acaso pudiera ser el maestro flamenco Gil de Brabante, artífice del retablo de la Anunciación del Monasterio de San Pedro el Viejo de Huesca, o del Retablo mayor de la Colegiata de Bolea, entre otras obras. sociales:

El siguiente gráfico presenta la distribución de bibliotecas por estratos

22 Vid. los dos inventarios de una misma biblioteca, la del Juan del Fierro, en AHPH. Protocolo de Sebastián de Canales, mayor, 687, ff. 53-56 (1564, enero, 23) y AHPH. Protocolo de Sebastián de Canales, mayor, 687, ff. 156- 159 (1564, marzo, 3). 


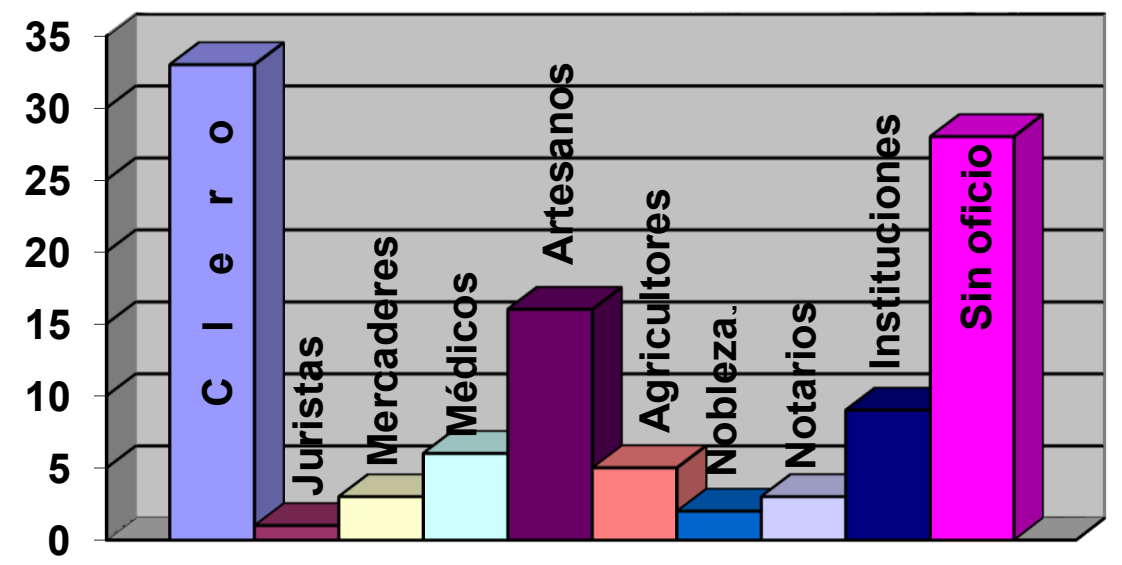

Gráfico 1: Porcentaje de bibliotecas por estrato social. Fuente: Elaboración propia.

Los 2.500 títulos localizados siguiendo la ya clásica clasificación de bibliotecas privadas de Víctor Infantes ${ }^{23}$ se distribuyen en:

a) 107 Bibliotecas prácticas formadas por una colección de no más de 20 libros que son de consulta directa, cuyos propietarios representan una amplia variedad de estratos sociales (bajo clero, mercaderes, médicos, agricultores, artesanos, notarios, instituciones). En un porcentaje muy elevado solo citan entre 1 y 5 libros. Es habitual que junto a los libros se mencione diverso material de escritura como papel, escrituras, reglas, plumas de escribir, anteojos, tinteros y libros de cuentas. Las lecturas comunes son: breviarios, horas, misales, Contemptus mundi, gramáticas, Fueros, Manual de confesores.

b) 31 Bibliotecas profesionales formadas por libros herramienta para ejercer el oficio, cuya colección puede llegar hasta los 60 volúmenes. En la mayor parte de las bibliotecas los libros se pueden identificar con mayor facilidad. Normalmente son miembros del clero y médicos los que poseen bibliotecas de este tipo. También se encuentra algún notario e institución eclesiástica. Las lecturas habituales son. ${ }^{24}$ Fueros de Aragón, el Formulario de actos extrajudiciales de Miguel del Molino, la

23 Víctor Infantes DE Miguel, «Las ausencias en los inventarios de libros y de bibliotecas», en Bulletin Hispanique, 99, 1 (1997) (Les livres des espagnols à l' Époque Moderne), pp. 281-292.

${ }^{24}$ En la biblioteca del médico Martín de San Juan entre sus 34 libros hay más libros de gramática y retórica que de medicina pues para acceder al título de médico en la Universidad Sertoriana debía haberse estudiado primero en la Escuela de Gramática y luego en la Facultad de Artes. Esto explicaría la preeminencia de lecturas que versan de las disciplinas del Trivium en bibliotecas donde se esperaría encontrar fundamentalmente libros científicos.

Titivillus, ISSN 2387-0915, ISSN-e 2603-9966, 3 (2017), pp. 67-90 
Summa Artis Notariae de Rolandinus Passageriis, la Gramática de Alexandre de Villadieu, las obras de Nicolás de Lyra, el De proprietatibus rerum de Bartolomé Anglicus, y las Epistolas de Juan de Yciar.

c) 24 Bibliotecas patrimoniales compuestas por una colección que puede llegar hasta los 300 libros. En ellas sus poseedores, que pertenecen al clero, principalmente, son juristas y, en menor medida, algún médico, entienden el libro como un objeto de trabajo y de consideración social. En los inventarios de estas bibliotecas es donde el notario describe las más bellas encuadernaciones e incluso en ocasiones tasa algunos de ellos. En su defecto también en estos inventarios es habitual encontrar citas como «Item, 172 volumenes de libros grandes y chicos». Entre estas lecturas hay un claro predominio de libros religiosos y de derecho.

d) 3 Bibliotecas museo en las que se considera al libro como un objeto de colección, que forma parte de un espacio propio, el estudio, que sería en esta época el germen de lo que en el siguiente siglo se conocería como gabinete de las maravillas, y donde el libro compartiría protagonismo con otros objetos valiosos y curiosos, como obras de arte, minerales, colecciones de insectos y otras piezas de coleccionista. Pertenecería a esta tipología la biblioteca del Obispo Diego de Arnedo, de la que el notario solo anotó el número de 524 libros y la biblioteca del Obispo Pedro del Frago, con 734 libros. $^{25}$ Añadir la recién localizada biblioteca del Obispo Martín Cleriguech y Cáncer, de la que se desconoce el número de libros pero sí se sabe su valor: trescientas cuarenta y cuatro libras jaquesas.

En la siguiente tabla se muestra un resumen de las 165 bibliotecas localizadas en la investigación de las que 3 de ellas pertenecientes al grupo de bibliotecas patrimoniales tienen varios inventarios de los mismos individuos realizados en diferentes actos y por distintos notarios. ${ }^{26}$

\footnotetext{
25 Vid. nota13.

26 Se trata de las mencionadas bibliotecas patrimoniales de los juristas Francisco Domínguez — de la que hay dos inventarios- y Jaime Morcat — de la que hay 3 inventarios-. Este es el motivo por el que en la tabla e relacionan 21 bibliotecas patrimoniales frente a las 24 referidas en el artículo.
} 


\begin{tabular}{|l|c|c|c|c|c|}
\hline Estrato social & $\begin{array}{l}\text { B. Práctica } \\
\text { (0-20 libros) }\end{array}$ & $\begin{array}{l}\text { B. Profesional } \\
\text { (hasta 60) }\end{array}$ & $\begin{array}{l}\text { B. Patrimonial } \\
\text { (hasta 300) }\end{array}$ & $\begin{array}{l}\text { B. Museo } \\
\text { (más de } \\
\text { 301) }\end{array}$ & $\begin{array}{l}\text { Indivi- } \\
\text { duos }\end{array}$ \\
\hline Nobleza & 5 & 1 & & & 6 \\
\hline Clero & 33 & 13 & 12 & 3 & 61 \\
\hline Mercaderes & 1 & 1 & & & 2 \\
\hline Prof. liberales & 10 & 8 & 8 & & 26 \\
\hline Base pobl. urb. & 21 & 1 & & & 14 \\
\hline Instituciones & 9 & 5 & 21 & 3 & 162 \\
\hline Sin oficio & 28 & 2 & & & 31 \\
\hline
\end{tabular}

Tabla 3. Distribución de inventarios por estrato social y por tipo de biblioteca. Fuente: Elaboración propia.

A continuación se indican la relación de los inventarios citados, como ejemplo, al hablar de los lectores y de los tipos de bibliotecas que tenían en función de su estrato social :

\begin{tabular}{|c|c|c|c|}
\hline 1575, septiembre, 10 & Alonso Cortés & Nobleza & Práctica (5) \\
\hline 1579, abril, 4 & Tomasa de Suelbes & Nobleza & Práctica (8) \\
\hline 1580, junio, 16 & Gracia de Mur, viuda de Martín de Lierta & Nobleza & Profesional (20) \\
\hline 1552 , agosto, 23 & Alonso de Aragón, abad de Montearagón & Clero & Profesional (50) \\
\hline 1552, noviembre, 24 & $\begin{array}{l}\text { Domingo de Ciria (maestre) prior del claustro y } \\
\text { canónigo de Montearagón }\end{array}$ & Clero & Patrimonial (97) \\
\hline 1574, octubre, 5 & Diego de Arnedo, Obispo de Huesca & Clero & Museo (540) \\
\hline 1576, septiembre, 14 & Eliseo Adrian, canónigo de Montearagón & Clero & Patrimonial (147) \\
\hline 1580, diciembre, 5 & $\begin{array}{l}\text { Juan Torregrosa, doctor en teología y maestro mayor } \\
\text { del Estudio de Huesca }\end{array}$ & Clero & Patrimonial (106) \\
\hline 1572, enero, 4 & Jaime de Fanos, mercader & Mercader & Práctica (4-10)) \\
\hline 1594, enero, 18 & Juan de la Fuente, droguero & Mercader & Efímeros \\
\hline 1533, febrero, 10 & Jaime de La Raga, notario público & $\begin{array}{l}\text { Profesión } \\
\text { Liberal }\end{array}$ & Profesional (16) \\
\hline 1555, septiembre, 7 & Jaime Morcat (micer) jurista oscense & $\begin{array}{l}\text { Profesión } \\
\text { Liberal }\end{array}$ & Patrimonial (164) \\
\hline 1560, mayo, 20 & Miguel Ram, doctor en medicina & $\begin{array}{l}\text { Profesión } \\
\text { Liberal }\end{array}$ & Patrimonial (180) \\
\hline 1586, septiembre, 30 & Juan Serra, doctor & $\begin{array}{l}\text { Profesión } \\
\text { Liberal }\end{array}$ & Patrimonial (132) \\
\hline 1590, diciembre, 20 & $\begin{array}{l}\text { Francisco Dominguez (micer) doctor en derecho, y su } \\
\text { mujer Catalina Adrian }\end{array}$ & $\begin{array}{l}\text { Profesión } \\
\text { Liberal }\end{array}$ & Patrimonial (115) \\
\hline 1593, octubre, 23 & Martin de Lizana, notario público oscense & $\begin{array}{l}\text { Profesión } \\
\text { Liberal }\end{array}$ & Profesional (22) \\
\hline 1547, marzo, 12 & Juan de la Rumbide, fustero, y Catalina Bibiot & Artesano & Práctica (3) \\
\hline 1547, septiembre, 15 & Gil de Braban, mazonero & Artesano & Profesional (32) \\
\hline 1556, febrero, 28 & Pedro del Val, labrador & Artesano & Práctica (1) \\
\hline 1564, enero, 23 & Ana compas, viudad de Juan del Fierro & Artesano & Práctica (5) \\
\hline 1564, marzo, 3 & Juan del Fierro, calderero & Artesano & Práctica (3) \\
\hline 1579, mayo, 14 & $\begin{array}{l}\text { Martin Marañón menor, zapatero y Carolina de la } \\
\text { Riba }\end{array}$ & Artesano & Práctica (5) \\
\hline
\end{tabular}

Tabla 4, Bibliotecas citadas, muestra de distribución por clase social. Fuente: Elaboración propia. 


\section{Lecturas y clasificación}

Una vez conocidos los libros que había y quién los tenía es necesario profundizar en qué tipo de lecturas poseían los oscenses. Para ello, tras valorar la utilización de una clasificación moderna, se optó por seguir una clasificación coetánea a la época estudiada ${ }^{27}$ que permitía ponderar adecuadamente el valor que tenían los libros en ese momento cronológico específico para sus dueños y ponerse en su lugar a la hora de decidir su clasificación en un grupo o en otro. ${ }^{28}$

Se optó por la desarrollada por Francisco de Araoz en su obra De bene disponenda bibliotheca impresa en 1631.29 Araoz es innovador en el modo de abordar una clasificación totalmente apriorística donde da cabida a los posibles títulos que pudieran ir engrosando la colección. Esta capacidad de abstracción de la que hace gala supone un elemento clave en la biblioteconomía actual, acostumbrada a trabajar con la Clasificación Décimal Universal, una clasificación también concebida de la misma manera. Este pensamiento abstracto no es común en otras clasificaciones contemporáneas a la de Araoz que clasifican las lecturas a la vez que las sitúan en los anaqueles de la biblioteca.

Sin embargo, se aprecian algunas deficiencias en el sistema de Araoz que, fiel a los preceptos tridentinos, incurre en el error de jerarquizar los saberes planteando una clasificación que primero trata de las materias humanas y va ascendiendo niveles hasta llegar a las materias que tratan de asuntos divinos. Araoz plantea 15 categorías divididas en 4 grupos: que separan lo profano —en el estrato más inferior- de lo divino - en el superior-

. Verbum o de la palabra (I-V).

. Res o del mundo (VI-VII).

. Homo o del hombre moral (VIII) y social (IX).

. De lo divino (X-XV).

El establecimiento de estas categorías agrupadas según niveles indispensables de conocimiento cuyo ascenso, como si de una escala se tratara, llevaría al hombre a encontrar la comunión con Dios, sin embargo,

\footnotetext{
${ }^{27}$ Hay que tener en cuenta que lo habitual en el siglo XVI era que las bibliotecas se organizasen por las materias del Trivium y el Quadrivium, más las de las Facultades de Teología, Derecho y Medicina. Luego, dentro de ellas los libros se ordenaban por tamaños.

28 Chartier, en su ensayo «La biblioteca sin muros» diserta sobre varios tipos de clasificación, como la de Gesner y François de la Croix du Maine; y disposición de los libros según los catálogos de algunas bibliotecas. Chartier da una visión de las acepciones etimológicas del término biblioteca en la Edad moderna. Vid. Roger CHARTIER, El orden de los libros: lectores, autores, bibliotecas en Europa entre los siglos XIV y XVIII, Madrid, Gedisa, 2005 (Lea; 4).

${ }^{29}$ Traducida y editada recientemente por José SOLís DE LOS SANTOS, El ingenioso bibliólogo Don Francisco de Araoz. (De bene disponenda bibliotheca, Matriti 1631), Sevilla, Universidad, 1997. La clasificación de Araoz se basa en buena parte en la de Gesner.
} 
limita cualquier tipo de flexibilidad que el carácter apriorístico de la clasificación pudiera concederle. Sin entrar en detalle, se apuntan razones como:

- la unión entre moral y ciencia característica de la religiosidad del momento que impide la separación de la ciencia y la religión;

- la fusión en la misma categoría entre ficción y realidad que se refleja en la clasificación conjunta entre historia y literatura de ficción;

- la clasificación de los libros en verso en una clase distinta de la prosa e independiente de su tema a excepción de los que con su métrica ensalcen a Dios que pertenecerían a la categoría de culto divino;

- la ausencia de un apartado de «Varios» que conferiría estabilidad a la clasificación queda anulada por el hecho de que Araoz no contempla que un libro tenga cabida más que en una única categoría; y

- las categorías 6 y 7, que aparentemente corresponden a la disciplinas del quadrívium, cuyas subdivisiones son rígidas secciones en función prácticamente de los oficios del momento — geómetras, músicos, astrónomos, agrónomos, estrategas, físicos, condimentadores, médicos- y no de las disciplinas científicas que puedan ir surgiendo.

Una vez aplicada esta clasificación a la investigación, puede apreciarse la distribución de libros por categorías. ${ }^{30}$

\begin{tabular}{|l|c|}
\hline Gramática & 76 \\
\hline Obras de referencia & 15 \\
\hline Oratoria & 87 \\
\hline Literatura en prosa & 79 \\
\hline Literatura en verso & 57 \\
\hline Ciencias exactas y tecnología & 68 \\
\hline Ciencias naturales y aplicadas & 68 \\
\hline Filosofía moral & 77 \\
\hline Derecho civil & 334 \\
\hline Derecho canónico & 316 \\
\hline Teología escolástica & 221 \\
\hline Sagrada Escritura & 132 \\
\hline Historia Sagrada & 59 \\
\hline Patrística & 182 \\
\hline Culto religioso & 371 \\
\hline TOTAL & $\mathbf{2 . 1 3 6}$ \\
\hline
\end{tabular}

Tabla 5, Clasificación de libros. Fuente: Elaboración propia

\footnotetext{
${ }^{30}$ Como se ha explicado antes, la cifra de 2.136 títulos citados en bibliotecas a los que hay que añadir las obras en varios volúmenes y otras de las que el notario cita el autor pero no indica cuántos volúmenes hay. La cifra hay se incrementa con los libros de las bibliotecas en las que solo se indica su número pero de las que se desconoce su composición. Por esto, conviene tomar como un recuento estimativo la cantidad de 2.500 ejemplares citados dada al principio.
} 


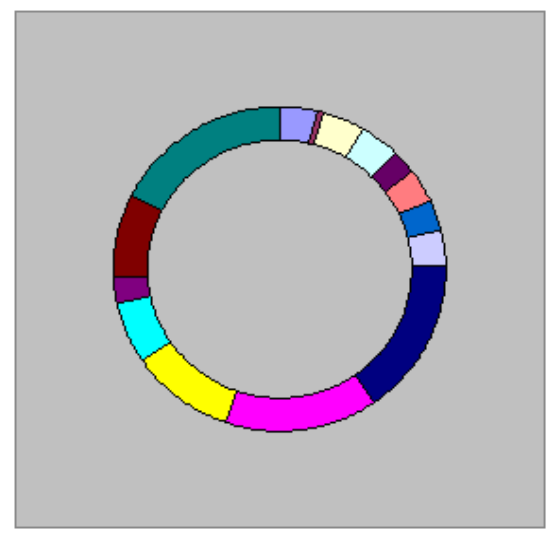

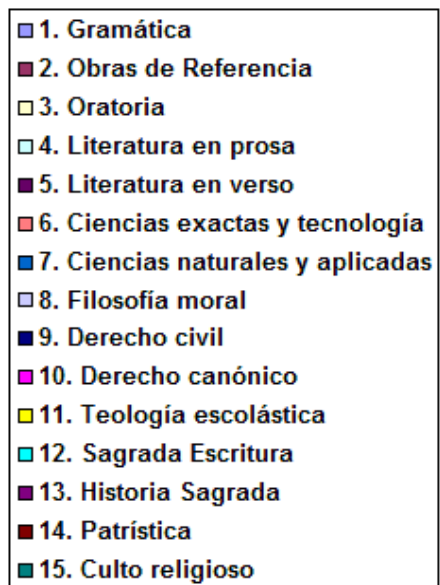

Gráfico 2, Distribución de libros por categorías. Fuente: Elaboración propia

En las siguientes líneas se ilustra con algún ejemplo varias de las lecturas más leídas por los oscenses siguiendo la clasificación por categorías de Araoz:

- 1. Gramática: en esta categoría se halla el diccionario políglota por antonomasia compuesto por Ambrogio de Calepio. El calepino, como lo citan habitualmente, aparece en 10 inventarios; por supuesto figuran también las obras de Elio Antonio de Nebrija que aparecen referenciadas como «un diccionario de Antonio de Nebrija», «un arte de Anthonio de Nebrisa en cuero colorado y doradas», «Bocabularium Antonii». A juzgar por las numerosas citas localizadas de la Grammatica frente a la única cita que aparece de Alexandre de Villadieu, autor de una de las gramáticas más estudiadas en las universidades, se aprecia que el nebrisense había irrumpido fuerte en las aulas de la Universidad Sertoriana. ${ }^{31}$ Se ha de destacar la obra del autor valenciano Juan Torrella, de quien Juan Torregrosa posee «Veinte y un libros de sintaxis de Torrellas encuadernado en papel». Parece que el maestro mayor de gramática apostaba por enseñar en las aulas la nueva sintaxis que se presentaba como alternativa a la de Nebrija.

- 2. Obras de referencia: los lectores Jaime de La Raga 32 —notario- y Domingo de Ciria ${ }^{33}$ — canónigo de Montearagón- possen la obra De proprietatibus rerum de Bartholomeus Anglicus, precursora de las enciclopedias y destinada a uso escolar. En ella se observa la importancia que posee la religión en todas las facetas del conocimiento, desde los asuntos divinos de los que

\footnotetext{
${ }^{31}$ La primera gramática en lengua vernácula sería una de las obras impresas en 1582 por el impresor de la universidad de Huesca, Juan Pérez de Valdivielso.

32 AHPH. Protocolo de Juan Canales, 651, ff. 38 v - 39 v y 48-51 (1533, febrero, 10).

33 AHPH. Protocolo de Juan de Rasal, 784, ff. 426 v - 431 v y 434-435 (1552, noviembre, 24).
} 
trata en sus primeros temas hasta llegar a los fenómenos de la naturaleza y los sentidos humanos.

- 3. Oratoria: la retórica entendida como el ars bene dicendi es uno de los pilares básicos de la enseñanza de cualquier centro universitario. Sin duda, entre las lecturas más apreciadas en las bibliotecas destaca el De oratore y las Orationes de Cicerón. ${ }^{34}$ La biblioteca que más obras posee de Cicerón es la del Abad de Montearagón Alonso de Aragón que debía ser un gran bibliófilo a juzgar por la descripción de las encuadernaciones de los libros que hace el notario: «Et primo, las obras de Tulio en nuebe cuerpos, todos dorados enquadernados y la enquadernacion dorada». Se menciona también a un profesor de retórica de la Universidad Sertoriana, Juan Costa y a su obra De utraque inventione oratoria \& Dialectica libellus, de las que tenía dos ejemplares el notario Martín de Lizana, uno de ellos «por encuadernan». ${ }^{35}$

- 4. Literatura en prosa: como se ha indicado previamente, la línea entre ficción y realidad era tenue a comienzos de la Edad Moderna. En esta categoría frecuentan las lecturas de obras de César como los Commentarii y obras de Cicerón como las Epistolae ad Atticum, de las que el doctor Martín de San Juan ${ }^{36}$ y Bernardo Bezón ${ }^{37}$ eran ávidos lectores; o el Libro de la coronica del Rey don Hernando del cronista de Aragón Jerónimo Zurita que tenía el licenciado Juan Segura, monje agustino y canónigo de Montearagón. ${ }^{38}$ Esta literatura biográfica compartiría espacio con lecturas como el Libro de las maravillas del mundo atribuida a John Mandeville, que era realmente el protagonista de la obra. En él narra en primera persona su viaje de peregrinación combinándolo con leyendas de las tierras por las que pasa y de los animales fantásticos - las maravillas - que observa. Se trata de una obra que, a pesar de ser una de esas historias mentirosas, al tomar forma de misión caballeresca hizo que los lectores lo vieran como un viaje autobiográfico.

- 5. Literatura en verso: entre las lecturas que pertenecerían a este grupo se encuentran Los Triumphos de Petrarca, ${ }^{39}$ y clásicos como Terencio, Virgilio o Ovidio, destacando este último con sus Epistolae Heroidum y sus Metamorphoseon. 40

\footnotetext{
${ }_{34}$ De oratore es un manual que en forma de diálogos enseña las distintas partes de la oratoria como elemento práctico de la retórica. En las Orationes, Cicerón lleva a la práctica las enseñanzas anteriores para recopilar una selección de citas sobre diversos temas legales y jurídicos de su época. Esta es la obra de las que más referencias se han encontrado.

35 AHPH. Protocolo de Andrés de Castro, 1065, ff. 656-663 (1593, octubre, 23).

36 AHPH. Protocolo de Guillermo Cleriguet, 1349, doc. 79 (1578, marzo, 20).

37 AHPH. Protocolo de Luis Climent, 988, ff. $43-45$ (1556, enero, 26).

38 AHPH. Protocolo de Pedro de Rasal, 1097, 1149-1152 v (1600, octubre, 16).

39 En poder del vicario de Yéqueda, Martín de Pueyo. Vid. AHPH. Protocolo de Andrés de Castro, 1065, ff. 195-197 v (1593, marzo, 31).

40 De Las Metamorfósis de Ovidio imprimiría Pérez de Valdivielso una edición en 1610, así que con seguridad no sería la citada en los inventarios que son de fecha anterior.
} 
- 6. Ciencias exáctas y tecnología: se reserva esta categoría para las disciplinas del quadrivium alterando su orden, tal y como explica Solis: nombrando primero la geometría — la medida del espacio terrestre-, posteriormente la música - el número en movimiento y su efecto en el hombre_- después la aritmética —el cálculo abstracto- y finalmente y en cuarto lugar la astronomía — la medición de los espacios celestes - ${ }^{41}$ No podía faltar en las bibliotecas el De sphaera mundi de Sacrobosco que difundió las bases de la astronomía siguiendo la teoría ptolemáica y a otros astrónomos árabes, convirtiéndose en uno de los primeros libros científicos impresos. Tres clérigos tenían este libro; dos de ellos canónigos del Montearagón, Domingo de Ciria $^{42}$ y Juan Segura; y los otros dos altos cargos de las parroquias oscenses, Luis Serra y Miguel Sangüés. ${ }^{43}$ Complementaria al desarrollo de la astrología surgiría la preocupación por la medida del tiempo y, con ello, la proliferación de repertorios de los tiempos y calendarios. Prueba de ello son los de Rodrigo Zamorano y de Andrés Li de los que hay una amplia representación en los inventarios. Por lo que respecta a la música destaca la lectura el Arte de canto llano contrapunto y canto de organo de Gonzalo Martínez de Bizcargui que figura entre los plúteos de 3 lectores.

- 7. Ciencias naturales y aplicadas: partiendo de la base del estudio de la filosofía de la naturaleza, sobre la posibilidad del hombre para interactuar con el mundo real y así no verse sometido únicamente a las leyes naturales sin poder cambiar su destino, Araoz incluye aquí también a los médicos por ser sus fuentes principales Aristóteles y Platón, a los preparadores de alimentos y condimentadores, agrónomos y los tratados sobre piedras y metales preciosos. Representan estas disciplinas lecturas como las de Aristóteles, Galeno de Pérgamo seguidor de Hipócrates y su teoría de los cuatro humores que dan lugar a los cuatro tipos de temperamento, y el doctor en teología de la Sertoriana Juan Huarte de San Juan con su Examen de ingenios para las ciencias. ${ }^{44}$ Una de las lecturas más frecuentes es el Libro de agricultura de Alonso de Herrera, libro que poseen el doctor Juan Serra, Jerónimo Serra ${ }^{45}$ y el canónigo Domingo de Ciria. Y en una de las bibliotecas, de nuevo la del notario Martín

\footnotetext{
${ }^{41}$ Op.cit. nota 28.

42 AHPH. Protocolo de Juan de Rasal, 784, ff. 426 v - 431 v y 434 r - 435 r (1552, noviembre, 24).

43 AHPH. Protocolo de Andrés de Castro, 1062, ff. 606-611 (1590, octubre, 29); AHPH. Protocolo de Andrés de Castro, 1059, doc. 92 (1586, marzo, 24).

${ }^{44} \mathrm{La}$ obra de Huarte fue impresa en el taller oscense en 1581, la teoría organicista expuesta en ella donde separa la filosofía natural de la teología le valió la entrada en el Índice de libros prohibidos en 1583. Más tarde su innovadora teoría le encumbraría a considerarle padre de la psicología. Vid. Pablo Cuevas Subías; Sergio Paúl Cajal, «El examen de ingenios para las ciencias de Juan Huarte de San Juan y la Universidad de Huesca», en Archivo de Filología Aragonesa, 70 (2014), pp. 115-144.

45 AHPH. Protocolo de Andrés de Castro, 1062, ff. 401-405 v (1590, julio, 12).
} 
de Lizana, aparece citado «Un libro de guisados» que probablemente se refiera a la obra de Ruberto de Nola.

- 8. Filosofía moral: en las escuelas (desde la antigüedad clásica) se leían las Fabulas de Esopo y estas lecturas pedagógicas y moralizantes no podían faltar en las bibliotecas oscenses, tal y como demuestra encontrarlas en manos del calderero Juan del Fierro, ${ }^{46}$ del canónigo Martín Sanz de Spin, ${ }^{47}$ dos lectores de clases sociales bien distintas. Está presente en De Oficiis de Cicerón, manual de conducta de cada hombre en función de su condición social que hace que el lector medieval y renacentista recibiera su lectura como un tratado de ética práctica, razón por la que su difusión fue muy amplia y puede encontrarse frecuentemente en los anaqueles de las librerías inventariadas. Figuran también las Epístolas familiares de Antonio de Guevara cuyo carácter moralista lleva a englobarla en esta categoría por encima del género epistolar en qué está escrita y que la hubiera llevado a clasificarla en la categoría 3 de oratoria. Guevara permite aproximarse a la sociedad del XVI nombrando hechos históricos y pensamientos de su época de forma razonada para que el lector obtenga un mejor aprovechamiento del consejo. 5 lectores tienen las «Epístolas» de Guevara, de ellos, Isabel Duarte, ${ }^{48}$ mujer de Pedro Martínez Gilberte, la tiene repetida.

- 9. Derecho civil: donde se clasifican los políticos y los juristas. Evidentemente, el Corpus Iuris Civilis de Justiniano y los comentarios al mismo son frecuentes en las bibliotecas de los juristas, grupo social ampliamente representado. Obras como las de Paulo de Castro o Philipo Decio son lecturas habituales. ${ }^{49}$ También el derecho positivo aragonés es frecuente en las citas, principalmente los fueros de Aragón. También figuran las obras del jurista aragonés Miguel del Molino. Citas como «Los fueros de Aragón, todos», «Un formulario de actos extrajudiciales», o «El repertorio de Molino» están muy presentes en los inventarios.

- 10. Derecho canónico: de forma similar a lo indicado en la categoría anterior, dada la cantidad de inventarios de miembros del clero, las lecturas sobre el Corpus Iuris Canonici y sus comentarios son frecuentes en los documentos. La unión que hace $\mathrm{Araoz}$ entre el derecho y la teología moral deja paso en esta categoría a las obras que ahondan en el fuero interno o de la

\footnotetext{
46 AHPH. Protocolo de Sebastián de Canales, mayor, 687, fol. 53-56 (1564, enero, 23).

47 AHPH. Protocolo de Andrés de Castro, 1054, ff. 96-101 (1579, enero, 4).

48 Archivo de la Catedral de Huesca (ACH). Protocolo de Gerónimo Pilarés, A-59, ff. 68-87 (1556, febrero, 1).

49 Probablemente, como dice Araoz no hace falta relacionar estos libros porque son fácilmente reconocibles por el lector por ser cosa «tan conocida y variada» y esta sea la razón por la que las citas genéricas abundan en los inventarios. Citas imprecisas como «Otra pieça de Paolo de Castro», o «Un drecho civil grande», «Una Instituta», «Un digesto» que permiten identificar el corpus completo al que pertenece la obra pero no siempre lleva a la identificación concreta de la obra, como puede ser «Una pieça de los consejos de Felipo Decio» que se corresponde a los Consilia.
}

Titivillus, ISSN 2387-0915, ISSN-e 2603-9966, 3 (2017), pp. 67-90 
conciencia. Así, la Summa de casibus conscientiae de Angel de Clavasio o el Manual de confesores y penitentes de Martín de Azpilcueta, destacan en las bibliotecas. ${ }^{50}$ Por supuesto, no podían faltar las lecturas sobre el Concilio de Trento que aparecen citadas bajo la referencia «Concilium Tridentinum», «Concilio de Trento en cuero, un cuerpo» $\mathrm{O}$ «Un Concilio tridentino en papel».

- 11. Teología escolástica: regida por el argumento de autoridad y bajo la máxima medieval por la que la filosofía se subordina a la teología, la escolástica nació como un método filosófico que buscaba la conciliación con la teología arguyendo mediante la razón una explicación a los misterios de la fe cristiana. En este marco no puede faltar el teólogo Pedro Lombardo conocido como «el Maestro de las Sentencias» autor de los Libri quattuor sententiarum que fue uno de los manuales de teología en todas las Universidades. 4 lectores oscenses poseían un ejemplar. Santo Tomás de Aquino y los teoréticos que le siguen como Jean Capreolus, así como los autores que se oponen al tomismo, como los seguidores nominalistas de Ockham y Duns Scoto, también forman parte del corpus de lecturas oscenses. Destaca, además, de manera notable la difusión de las obras de Domingo de Soto. ${ }^{51}$ Ya solo en la biblioteca de Jerónimo Morales, maestro y clérigo, se encuentran 5 obras distintas suyas. ${ }^{52}$

- 12. Sagrada Escritura: esta categoría está referida a la teología positiva que anhela el conocimiento de Dios a través de la lectura de las Sagradas Escrituras fundamentando sus razonamientos en la experiencia que otorgan la tradición y los padres de la iglesia. La Biblia y sus comentarios, como los del franciscano Nicolás de Lira son las lecturas por excelencia.53 Otro de los autores más leídos fue François Titelmans y su Elucidationes in omnes psalmos.

- 13. Historia Sagrada: destinada a aquellos libros que son efecto de la lectura de la Biblia y los libros sagrados, es decir, de los que hablan de la historia de la iglesia, del pensamiento y de las vidas de santos y mártires. De lectura edificante debía ser la Historia de Vitis Pontificum Romanorum de Bartolomeo Platina. La Vita Christi, que fue la primera vida que escribió sobre Jesús el cartujo Ludolfo de Sajonia, es lectura principal en la época. Destacar las ocho bibliotecas cuyos propietarios, de distinta procedencia social, poseen el Flos Sanctorum; libro que permitía realizar una lectura breve del santo asignado cada día por el calendario litúrgico. Esta obra no operaba en los lectores solo con la continuidad de un modelo de virtud, sino que también constituía una forma de lectura de entretenimiento según el gusto espiritual de

\footnotetext{
50 Citadas como «Suma angelica», «otro libro intitulado Suma Angelica, quatro sueldos», «Un manual de Navarro» o «Navarro de penitentes». Este último persigue la formación de párrocos para ejercer correctamente su labor de cura de almas, de ahí su nombre de «manual» y su difusión en las bibliotecas oscenses.

${ }^{51}$ La mayor parte de obras localizadas de Domingo de Soto son De iustitia et iure, De natura et gratia, In dialecticam Aristotelis y Super octo libros phisicorum Aristotelis comentaría.

52 AHPH. Protocolo de Martin Arascués, 1113, ff. 52-53 (1592, mayo, 20).

53 Aunque son varias las obras localizadas en los inventarios de Nicolás de Lyra, la que se cita más veces es la Postilla super quattuor evangelistas.
} 
la época. Probablemente ese fuera el motivo de que se haya podido encontrar este libro en manos del ya mencionado zapatero Martín Marañón, como en manos del doctor Juan Serra o en las de Catalina Adrián, ${ }^{54}$ viuda del doctor en derecho micer Francisco Domínguez, que al volverse a casar lo aporta como dote matrimonial por una cantidad de «veynte sueldos».

- 14. Patrística: dedicada a los padres y doctores de la iglesia, no podían faltar aquí las obras de San Agustín, San Buenaventura, San Bernardo, San Jerónimo y Santo Tomás de Aquino. Una vez más ocurre como con los textos legales y canónicos, que fueron obras tan difundidas que el notario en numerosas ocasiones apenas consignaba el autor y el número de volúmenes («las obras de Sanct Agustin en onze tomos»). Araoz también clasifica aquí autores como Luis de Granada, cuyas obras responden a una lectura de tipo doctrinal donde se conjuga la teología moral y la filosofía moral para intentar dar respuesta a dilemas morales por medio de la fe. En esta línea se situaría también el Libro de la vanidad del mundo de Diego de Estella; libros en poder de Juan Serra y del vicario Martín de Pueyo.

- 15. Culto religioso: es el último escalón, despojado el lector de todo conocimiento superfluo que le impida adentrarse en el terreno de la fe, Araoz reserva esta categoría a la poesía religiosa como el Divina y varia poesia de Jaime de Torres y de quien el maestro mayor del Estudio General de Huesca, Juan de Torregrosa tenía «diez y seis libros de paper de divina y varia poesia de fray Torres»,55 a los libros liturgicos como Breviarios, Libros de horas, «un entonario grande moderno çaragoçano» y alguno más, ${ }^{56} \mathrm{y}$ las lecturas piadosas que pretenden servir de guía espiritual para los fieles y párrocos. Sería el caso del Cathecismo provechoso de Alonso de Orozco o del Libro de la oracion de Andrés Capilla.

Se ha concentrado en estas líneas tan solo una breve muestra de las lecturas más citadas que, como cabe esperar, se localizan en su mayoría en las más nutridas bibliotecas halladas en los inventarios: las de teólogos y juristas, pues no en vano, las principales facultades de la Universidad Sertoriana fueron las de Teología y las de Derecho Canónico y Civil. Aunque con mucho menor volumen resultan muy interesantes aquellas bibliotecas enmarcadas en el grupo de bibliotecas prácticas y de profesionales poseedoras de un pequeño fondo, pues las primeras citan el único o los pocos libros que tienen; y las segundas después de descontar los libros que utilizaría el propietario para ejercer su profesión dejan entrever las lecturas que serían leídas por placer. Esto es, aquellas lecturas que reflejan a un lector que si tuviera posibles, o hubiera dejado inventario, leería a Esopo y las Epístolas familiares de Antonio de Guevara..., tendría un breviario o unas horas, su propietario se deleitaría con la

\footnotetext{
54 AHPH. Protocolo de Andrés de Castro, 1063, ff. 355-375 v (1591, agosto, 30).

55 Actualmente en prensa, Laura FONTOVA SANCHO, «El maestro mayor Torregrosa y su relación con la imprenta universitaria oscense (1580)».

56 Hasta ocho citas similares a la expuesta se pueden identificar con la obra de Intonario general para todas las iglesias de España en el qual se ha añadido los ochos tonos o modos de Miravete.
} 
Vida y crónica del gran Capitán de Paolo Giovio, o con el Flos sanctórum, ampliaría sus conocimientos con la Verdadera información de la Tierra Sancta de Antonio de Aranda o con el Fasciculus temporum de Wernerius Rolevinck, disfrutaría con la Silva de varia lection de Pedro Mejía y, por qué no, se interesaría leyendo el Contemptus mundi, el Lunario como el de Bernat de Granollachs o, incluso, el Libro de guisados de Ruberto de Nola. ${ }^{57}$

\section{Conclusiones}

Del estudio se deduce una evolución del tipo de bibliotecas a lo largo del siglo que se puede observar en la siguiente tabla.

\begin{tabular}{|c|c|c|c|c|}
\hline Años & B. Práctica & B. Profesional & B. Patrimonial & B. Museo \\
\hline $1501-1525$ & 9 & 1 & 1 & \\
\hline $1526-1550$ & 19 & 6 & 1 & \\
\hline $1551-1575$ & 48 & 8 & 10 & 1 \\
\hline $1576-1600$ & 33 & 15 & 12 & 2 \\
\hline
\end{tabular}

Tabla 6: Evolución de bibliotecas por períodos. Fuente: Elaboración propia

Aumenta la presencia de bibliotecas privadas a partir de la segunda mitad de siglo. La razón puede obedecer a dos supuestos: la gente cada vez acude más al notario para dar fuerza legal a sus acto; o en ese incremento también puede haber influido, en especial en el último cuarto de siglo, la presencia de un impresor universitario, Juan Pérez de Valdivielso, y de dos libreros, Pedro de Pisa y Diego López que también trabajaron para la Universidad. Se han encontrado en bibliotecas, especialmente de profesores, libros impresos por Pérez de Valdivielso de obras que escribieron otros profesores o estudiantes que pasaron por las aulas de la Sertoriana. Sería el caso citado antes de Juan Torregrosa, maestro mayor de la Escuela de Gramática, que tenía varios ejemplares del Divina y varia poesía de Jaime Torres, ${ }^{58}$ o del doctor Juan Serra canónigo de la Seo vinculado al Consejo de la Universidad, que tenía cuatro ejemplares del Examen de ingenios para las sciencias de Huarte de San Juan. ${ }^{59}$ No

\footnotetext{
57 Vid. bibliotecas de Jaime de la Raga, notario (16 libros) en AHPH. Protocolo de Juan Canales, 651, ff. 38 v - 39 v y 48-51; Isabel Duarte, viuda de Pedro Martínez Gilberte (9 libros) en ACH. Protocolo de Gerónimo Pilarés, A-59, ff. 68-87; Martín Marañón, zapatero (5 libros) en AHPH. Protocolo de Martín Lizana y Rosillo, 921, ff. 100- 103; Pedro Villamana, presbítero (11 libros) en AHPH. Protocolo de Andrés de Castro, 1064, ff. 538-540 v.; Martín de Lizana, notario (22 libros) en AHPH. Protocolo de Andrés de Castro, 1065, ff. 656-663.

58 AHPH. Protocolo de Luis de Navarro, 962, ff. 348-352 (1580, diciembre, 5).

59 Vid. nota 27. Vid. AHPH. Protocolo de Martín Arascués, 844, ff. 243-247 v (1586, septiembre, 30).
} 
es de extrañar, entonces, que varias de las bibliotecas profesionales y patrimoniales más importantes pertenezcan a profesores universitarios.

De lo anterior, se infiere que la mayor parte de las colecciones mayores están en mano de altos cargos del clero y de profesores de la Universidad. La variedad de temáticas que componen estas bibliotecas va en consonancia con el número de volúmenes que tienen. No obstante, se observa un predominio del libro religioso y jurídico. En las bibliotecas de médicos, además de libros científicos, aparecen bastantes libros de filosofía natural, y de autores latinos y griegos. Esto se debe, principalmente a que para acceder a cualquiera de las facultades mayores se debía cursar primero en la facultad menor de Artes. Y para acceder a Artes, se debían superar los cursos de la Escuela de Gramática donde se enseñaba lengua latina, lengua griega, retórica, dialéctica y otras disciplinas de las artes sermocinales que prepararan a los alumnos para continuar estudios superiores en la Universidad oscense.

Los índices de lectura son similares al del resto de ciudades con estudios sobre lectura en la Edad moderna, situados entre un 20-30\%, y en concreto para Huesca en un $23 \%$. No obstante, se debe tener en cuenta que los inventarios postmortem solo recogen un pequeño porcentaje de la población que es la que acudía al notario a que diera fe de sus negocios. Este dato, que puede sesgar la muestra, debe manejarse con prudencia a la hora generalizar conclusiones sobre hábitos lectores de toda una población; pues la ausencia del resto de bibliotecas no documentadas no indica que los libros no circularan igualmente por otros sectores, no tan representados en los inventarios.

$\mathrm{Al}$ analizar los datos y ver la evolución, contenido y propiedad de estas bibliotecas, se confirma la hipótesis de otros autores al intuir una mayor actividad cultural en la ciudad en este siglo, de la que habitualmente se ha considerado. ${ }^{60}$ Argumento que justifica en sí mismo el valor de la muestra estudiada.

${ }^{6}$ Vid. María Esquiroz Matilla, «Relaciones artísticas (plateros, escultores, pintores, bordadores y arquitectos) en Huesca durante el siglo XVI», en Actas del V Congreso de Arte Aragonés (5. 1989. Zaragoza), Zaragoza: Departamento de Cultura y Educación, 1989, pp. 527-548.

Titivillus, ISSN 2387-0915, ISSN-e 2603-9966, 3 (2017), pp. 67-90 